\title{
Diffusion tensor imaging point to ongoing functional impairment in HIV-infected children at age 5, undetectable using standard neurodevelopmental assessments
}

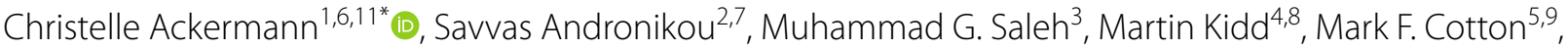 \\ Ernesta M. Meintjes ${ }^{3,10}$ and Barbara Laughton ${ }^{5}$
}

\begin{abstract}
Background: Perinatal HIV infection negatively impacts cognitive functioning of children, main domains affected are working memory, processing speed and executive function. Early ART, even when interrupted, improves neurodevelopmental outcomes. Diffusion tension imaging (DTI) is a sensitive tool assessing white matter damage. We hypothesised that white matter measures in regions showing HIV-related alterations will be associated with lower neurodevelopmental scores in specific domains related to the functionality of the affected tracts.

Methods: DTI was performed on children in a neurodevelopmental sub study from the Children with HIV Early Antiretroviral (CHER) trial. Voxel-based group comparisons to determine regions where fractional anisotropy and mean diffusion differed between HIV+ and uninfected children were done. Locations of clusters showing group differences were identified using the Harvard-Oxford cortical and subcortical and John Hopkins University WM tractography atlases provided in FSL. This is a second review of DTI data in this cohort, which was reported in a previous study. Neurodevelopmental assessments including GMDS and Beery-Buktenica tests were performed and correlated with DTI parameters in abnormal white matter.

Results: $38 \mathrm{HIV}+$ children (14 male, mean age 64.7 months) and 11 controls ( 4 male, mean age 67.7 months) were imaged. Two clusters with lower fractional anisotropy and 7 clusters with increased mean diffusion were identified in the HIV+ group. The only neurodevelopmental domain with a trend of difference between the HIV+ children and controls $(p=0.08)$, was Personal Social Quotient which correlated to improved myelination of the forceps minor in the control group. As a combined group there was a negative correlation between visual perception and radial diffusion in the right superior longitudinal fasciculus and left inferior longitudinal fasciculus, which may be related to the fact that these tracts, forming part of the visual perception pathway, are at a crucial state of development at age 5 .

Conclusion: Even directed neurodevelopmental tests will underestimate the degree of microstructural white matter damage detected by DTI. The visual perception deficit detected in the entire study population should be further examined in a larger study.
\end{abstract}

Keywords: HIV, Cognitive functioning, ARV, DTI, Functional anisotropy, White matter

*Correspondence: ca@sun.ac.za

1 Department of Radiodiagnosis, Faculty of Medicine and Health Sciences, University of Stellenbosch, Tygerberg, South Africa

Full list of author information is available at the end of the article

\section{Manuscript Background}

It is well established that perinatally acquired HIV infection negatively impacts cognitive functioning [1]. The 
principal domains affected vary with limited data from countries where HIV is prevalent. A recent meta-analysis of 22 studies (37\% from sub-Saharan countries) on vertically infected children aged 6 to 18 years, found that the main cognitive domains affected by HIV are working memory, processing speed and executive functioning [2].

Studies show that commencing combination antiretroviral therapy (ART) before 6 months in perinatally HIV-infected $(\mathrm{HIV}+)$ infants improves neurodevelopmental and clinical outcomes [3-6]. Concerns that ART might cause neurotoxicity and that adherence may wane, led to planned treatment interruption studies, which showed safety and no effect on short term neurocognition $[7,8]$. The clear advantage of early time-limited over deferred-continuous therapy for clinical outcomes was demonstrated in the Children with HIV Early Antiretroviral (CHER) trial [9]. Recently, Laughton et al. reported neurodevelopmental outcomes over 5 years in a CHER sub-study. Neurodevelopmental outcomes were similar between the treatment arms (delayed continuous ART or early ART with interruption at 40 or 96 weeks) and uninfected controls. The only exception was visual perception, measured on the Beery Visual Perception subtest, where all HIV+ arms performed significantly worse. This deficit was neither detectable on the Beery visual motor integration test (Beery-VMI) [10] nor the Griffiths Mental Development Scales (GMDS) [11].

Neuroimaging is instrumental in describing HIV effects on brain macro- and microstructure [12]. Specifically, diffusion tensor imaging (DTI) can be used to examine the nature of white matter (WM) damage through quantitative parameters such as fractional anisotropy (FA) and mean diffusivity (MD) [13-17]. Loss of axonal integrity decreases FA and increases MD, however, increased FA may also indicate diminished complexity of the axonal matrix due to loss of crossing fibres [18]. We previously published a DTI study on HIV+ children (mean age 5.7 years) from the cohort studied by Laughton et al., and demonstrated WM abnormalities of the projectional fibres of the corticospinal tracts (CST) and also association fibres of the superior longitudinal fasciculus (SLF), inferior longitudinal fasciculus (ILF), inferior frontal occipital fasciculus (IFOF) and uncinate fasciculus (UF). Children on continuous ART from within the first year of life had less WM damage than those randomised to treatment interruption. This was an interesting finding when considering that Laughton et al. showed that neurodevelopmental outcome at 5 years was not adversely affected by planned treatment interruption $[11,18]$.

The aim of the current study was to examine associations of FA and MD values in regions shown to be significantly different between HIV+ children and controls in the aforementioned DTI study [18], with directed neurodevelopmental scores. The latter were identified as those tests related to the expected function of involved WM tracts, for example CST and motor development, as opposed to the full battery of neurodevelopmental tests. We hypothesised that WM measures in regions showing HIV-related alterations would be associated with lower neurodevelopmental scores in specific domains related to the functionality of the affected WM tracts.

\section{Methods \\ Subjects}

The study group is uniquely homogeneous in that all the children began ART before 18 months, are from the same socioeconomic background and have a narrow age range.

56 Xhosa children enrolled in a neurodevelopmental sub study of the CHER trial $[9,19]$ in Cape Town, South Africa underwent magnetic resonance imaging (MRI) of the brain at 5 years of age. The group comprised HIV+ children who commenced ART early and age-matched, HIV-uninfected controls from a parallel vaccine study, with informed consent from parents or caregivers [20].

Inclusion criteria for the neurodevelopmental substudy were: birth weight $>2000$ g, normal neurological examination at a clinical visit near three months of age and no central nervous system problems or dysmorphic syndromes.

\section{The CHER trial}

The CHER trial (the source of our patient population) was a two-centre study in which HIV + infants between 6 and 12 weeks of age with CD4 $\geq 25 \%$ were randomized to one of three treatment strategies: ART deferred (ARTDef) until indicated; early limited ART for 40 weeks (ART-40 W); or early limited ART for 96 weeks (ART$96 \mathrm{~W})$. Continuous ART was initiated in ART-Def when the CD4 declined below 25\% in the first year of life and $20 \%$ thereafter or for Centres for Disease Control severe stage $B$ or $C$ disease. The same criteria applied to restarting ART in ART-40 W and ART-96 W. Infants with a $\mathrm{CD} 4 \%<25 \%$ were enrolled into a separate group (part B), initially to be randomised into ART-40 W and ART-96 W, but then retained on early continuous ART. The entire cohort comprised $451 \mathrm{HIV}$ + infants below 12 weeks of age, of which 115 were enrolled in Cape Town [9].

First-line ART was lopinavir-ritonavir, lamivudine and zidovudine; only one child was on second line therapy comprising Didanosine, Abacavir with Nevirapine. Most 
mothers participated in the prevention of mother to child transmission program, which included zidovudine antenatally from 32 weeks and for infants a single dose nevirapine at delivery and zidovudine for 7 days.

\section{Neurodevelopmental assessments}

The GMDS extended revised version (2-8 years) was performed at 5 years of age [21]. The GMDS assesses neurodevelopment on the subscales: locomotor, personal-social, hearing and language, eye and hand co-ordination, performance (visuospatial skills including speed and precision) and practical reasoning (Table 1). A global GMDS score is also obtained. Standardized translations into IsiXhosa and Afrikaans were used. One of two pediatricians conducted the assessments, assisted by a GMDS-trained translator. We converted raw scores into age equivalents using standardized norms and calculated a quotient as a percentage of each child's chronological age, using the United Kingdom norms with a mean of 100 and standard deviation of 15 [21, 22], Significant developmental delay was regarded as quotients below 70. The Beery-Buktenica tests of visual-motor integration (Beery-VMI), visual perception and motor coordination (6th edition) were also administered (Table 1) [23]. Standard scores were calculated from raw scores using
USA norms. While these developmental tests are not standardised for South African children, they are often used and considered culturally fair and reliable [21, 24, 25].

Baseline laboratory and clinical data at enrolment and within 6 months of MRI scan, including CD4, CD8 parameters and viral load (VL) were obtained from the CHER database. VL $>750,000$ copies $/ \mathrm{mL}$ were assigned as 750001 and those $<400$ copies $/ \mathrm{mL}$ as 399 (viral suppression).

\section{Ethics approval for the study was obtained from ethics boards of all institutions involved MRI data acquisition}

The children were imaged on a 3T Siemens Allegra MRI (Erlangen, Germany), without sedation while watching an age-appropriate feature film, using structural $\mathrm{T} 1$ imaging followed by 2 DTI acquisitions with opposite phase encoding directions using a twice-refocused spin echo sequence [26]. The 3D echo planar imaging (EPI) navigated [27] multiecho MPRAGE [28] (MEMPR) sequence was acquired in a sagittal orientation with the following parameters: FOV $224 \times 224 \mathrm{~mm}, 144$ slices, TR $2530 \mathrm{~ms}$, TE $1.53 / 3.19 / 4.86 / 6.53 \mathrm{~ms}$, TI $1160 \mathrm{~ms}$,

Table 1 Description of abilities assessed with the GMDS and Beery-Buktenica test

\begin{tabular}{|c|c|c|}
\hline \multicolumn{3}{|c|}{ Griffiths mental development scales } \\
\hline Subscale & \multicolumn{2}{|l|}{ Description of abilities assessed } \\
\hline Locomotor & \multicolumn{2}{|c|}{ Balance and stability-jumping over hurdles, balancing on one leg, skipping and running } \\
\hline Personal-social & \multicolumn{2}{|c|}{ Self-care including dressing, washing, tying shoe laces and being able to provide full name and address } \\
\hline Hearing and language & \multicolumn{2}{|c|}{$\begin{array}{l}\text { Receptive and expressive language is assessed } \\
\text { Naming objects and describing their use } \\
\text { Children are required to freely talk about a large/busy picture where vocabulary, sentence structure, pror } \\
\text { descriptive words are assessed } \\
\text { Auditory short-term recall with repetition } \\
\text { Naming colors, similarities opposites and descriptive }\end{array}$} \\
\hline Eye and hand Co-ordination & \multicolumn{2}{|c|}{$\begin{array}{l}\text { Free drawing of a person and a house. Copying geometric shapes } \\
\text { Writing name and copying letters } \\
\text { Cutting and folding paper and threading beads }\end{array}$} \\
\hline Performance & \multicolumn{2}{|c|}{$\begin{array}{l}\text { Visuo-spatial skills including speed and precision } \\
\text { Completing form boards and block patterns which are timed }\end{array}$} \\
\hline Practical reasoning & \multicolumn{2}{|c|}{$\begin{array}{l}\text { Closest to arithmetical reasoning: counting blocks, knowing days of the week, high/low, long/short, heavy/light, middle } \\
\text { and concept of speed. Short term memory of items shown } \\
\text { Arranging sequences of cards to tell a story }\end{array}$} \\
\hline General Griffiths Quotient: & Average of the 6 subtests above & \\
\hline \multicolumn{3}{|c|}{ Beery-Buktenica test of visual motor integration } \\
\hline Beery VMI & & $\begin{array}{l}\text { Child is required to copy various geometric forms and draw them below } \\
\text { the example figure }\end{array}$ \\
\hline Beery motor Co-ordination & & $\begin{array}{l}\text { Draw the same geometric forms by joining dots and keeping within the } \\
\text { guidelines. Draw as many as can within a time limit }\end{array}$ \\
\hline Beery visual perception & & $\begin{array}{l}\text { Identify shape out of a few that matches the example. Do as many as } \\
\text { can within a time limit }\end{array}$ \\
\hline
\end{tabular}


flip angle $7^{\circ}$, voxel size $1.3 \times 1.0 \times 1.0 \mathrm{~mm}^{3}$. DTI was performed in 30 directions with b-value $1000 \mathrm{~s} / \mathrm{mm}^{2}$, voxel size $2 \times 2 \times 2 \mathrm{~mm}^{3}$, TR/TE $9500 / 86 \mathrm{~ms}$, and 4 volumes with $\mathrm{b}=0 \mathrm{~s} / \mathrm{mm}^{2}$.

MRIs of children with motion corruption, showing incidental brain abnormalities, interslice instabilities or with an interval of over a year from the GMDS were excluded.

\section{Data analysis}

DTI data were previously analysed and reported in a study describing the distribution and nature of white matter abnormalities as well as the benefit of early treatment [18].

\section{Preprocessing}

Diffusion weighted volumes with signal dropout or motion corrupted slices were removed, and diffusion encoding scheme adjusted, with a constraint that the same volumes be removed in both DTI acquisitions. Co-registration and susceptibility correction were performed. Briefly, co-registration of individual volumes to the first unweighted image was performed using linear affine (12 degrees of freedom) transformation (FLIRT) in FSL (Oxford Centre for Functional Magnetic Resonance Imaging of the Brain, Oxford, UK). Subsequently, these images were imported to MATLAB (Mathworks, Natick, MA) for susceptibility correction and outlier rejection. Outliers of each acquisition were examined by first calculating z-scores based on 25 and 75 percentile limits; data points above 3 standard deviations beyond the mean were discarded. The two acquisitions were combined into a single corrected image; FA, MD and eigenvalue $\left(e_{1}, e_{2}\right.$, and $\left.e_{3}\right)$ images were generated. The first eigenvalue $\left(e_{1}\right)$ was $\mathrm{AD}$; the remaining two were used to compute $\mathrm{RD}$ $\left(\mathrm{e}_{23}=\left[\mathrm{e}_{2}+\mathrm{e}_{3}\right] / 2\right)$.

\section{Coregistration}

The FA images were first co-registered to corresponding structural images to achieve intra-subject alignment. Structural images of all subjects were then co-registered to a 'most representative' control image, then subsequently co-registered to the National Institutes of Health paediatric MRI Data repository T1-template image for children aged 4.5-8.5 years with isotropic resolution $1.0 \times 1.0 \times 1.0 \mathrm{~mm}^{3}$ using linear (FLIRT) and non-linear (FNIRT) co-registration algorithms in FSL. FA images were warped using the same transforms for inter-subject alignment. The same transforms were applied to MD, AD and RD images. A WM binary mask was generated for each subject by applying a FA threshold of 0.2 . Individual masks were multiplied to generate a final binary image representing WM regions where $\mathrm{FA} \geq 0.2$ in all subjects. The binary image was multiplied with the co-registered FA and MD images of each subject to localise statistical analyses, explained below, to the same WM regions.

Voxel-based group comparisons were performed in FSL to determine regions where FA and MD differed significantly between HIV + and control children. To account for multiple comparisons when determining significant clusters, AFNI's AlphaSim command was used with overall significance level $\alpha=0.05$ and individual voxel-wise significance level $p=0.01$. FWHM values ranged between 3.8 and $5.2 \mathrm{~mm}$ across the masked thresholded WM masks and we performed 5000 Monte Carlo simulations. Clusters of at least $258 \mathrm{~mm}^{3}$ were significant at these levels.

Locations of clusters showing group differences were identified using the Harvard-Oxford cortical and subcortical and John Hopkins University WM tractography atlases provided in FSL and an MRI atlas of human WM anatomy [29, 30], For each cluster, average FA and MD, and corresponding $\mathrm{AD}$ and $\mathrm{RD}$ values, were extracted.

\section{Statistical analysis}

Categorical variables were summarised using frequency and percentage frequency distributions overall and by group. Continuous measurements were summarised using means and standard deviation. Variables were compared between the groups using Chi square tests and ANOVA.

Specific functionality of the WM tracts with clusters of abnormal FA and MD in the HIV+ group compared to controls, were identified, right and left sided clusters were analysed separately. We used a directed approach to select neurodevelopmental tests that would closely match this functionality for correlation.

Spearman correlation was used to test for relationships between directed developmental scores and FA and MD values in affected regions. Correlations were performed as a combined group (HIV+ and controls) as well as controls and HIV + groups separately.

\section{Results}

Seven of 56 children assessed were excluded: one HIV + child whose structural image was motion corrupted, one control child with incidental periventricular leukoencephalopathy, two HIV+ children with data interslice instabilities, 2 control children in whom GMDS at age 5 were not performed, $1 \mathrm{HIV}+$ child with a period of more than 1 year and 2 months between the Griffiths analysis and the MRI scan. We therefore present data for $38 \mathrm{HIV}+$ children (mean $\pm \mathrm{SD}=5.4 \pm 0.3$ years; 14 boys) 
Table 2 Demographics and neurodevelopmental scores of the HIV+ group and controls

\begin{tabular}{|c|c|c|c|}
\hline & HIV+ & Controls & $p$ \\
\hline N & 38 & $11 *$ & - \\
\hline Gender (M/F) & $14 / 24(37 \% / 63 \%)$ & $4 / 7$ (36\%/64\%) & $0.97\left(x^{2}\right)$ \\
\hline Age at Griffiths (months) & $60.9(1.3)$ & $63.3(4.8)$ & 0.12 \\
\hline Range & $58.0-64.5$ & $59.5-71.0$ & - \\
\hline Age at scan (months) & $64.7(3.5)$ & $67.7(5.5)$ & 0.11 \\
\hline Range & $58.8-74.4$ & $61.2-74.4$ & - \\
\hline Time between Griffiths and scan (days) & $119.2(104.3)$ & $128.3(131.8)$ & 0.81 \\
\hline Range & $0-386$ & $21-392$ & - \\
\hline Age starting ART (weeks) & $18(16.8)$ & NA & - \\
\hline Range & $7.0-75.7$ & & - \\
\hline Cumulative Time on ART (weeks) & $234(50.8)$ & NA & - \\
\hline CD4 & & NA & - \\
\hline Baseline & $1965.4(939.8)$ & - & - \\
\hline Nadir & $703.2(391.6)$ & - & - \\
\hline At scan & $1132.7(480.7)$ & - & - \\
\hline CD4\% & & NA & - \\
\hline Baseline & $34.5(10)$ & - & - \\
\hline Nadir & $20.4(6.5)$ & - & - \\
\hline At scan & $35.2(8.2)$ & - & - \\
\hline CD8 & & NA & - \\
\hline Baseline & $1693.3(899.3)$ & - & - \\
\hline Nadir & $575.4(329.1)$ & - & - \\
\hline At scan & $1025.7(536.9)$ & - & - \\
\hline \multicolumn{4}{|l|}{ Griffiths Q scores } \\
\hline Locomotor & $96.1(16.2)$ & $93.0(11.9)$ & 0.57 \\
\hline Personal social & $90.8(9.4)$ & $96.4(9.0)$ & 0.08 \\
\hline Language & $75.4(10.7)$ & $77.7(10.7)$ & 0.53 \\
\hline Eye hand coordination & $85.4(9.0)$ & $84.3(12.2)$ & 0.74 \\
\hline Performance & $75.4(10.5)$ & $78.0(19.5)$ & 0.57 \\
\hline Practical reasoning & $76.7(8.6)$ & $75.2(11.4)$ & 0.65 \\
\hline General & $83.5(6.5)$ & $84.1(8.3)$ & 0.81 \\
\hline \multicolumn{4}{|l|}{ Beery-Buktenica } \\
\hline Visual motor integration & $91(9.1)$ & $87.4(7.2)$ & 0.23 \\
\hline Visual perception & $76.7(14.7)$ & $83.1(13.7)$ & 0.22 \\
\hline Motor co-ordination & $94.8(8.3)$ & $93.2(10.4)$ & 0.59 \\
\hline
\end{tabular}

Values: mean (standard deviation) unless otherwise stated

* 9 HIV exposed and uninfected, 2 unexposed

and 11 healthy controls (mean $\pm \mathrm{SD}=5.6 \pm 0.5$ years; 4 boys, 9 HIV exposed) (Table 2).

The HIV + and control groups did not differ for demographic variables (all $p$ 's $>0.1$ ); or on the interval between scan and Griffiths, which was 123.8 days on average. The groups did not differ on the GMDS (all $p$ 's $>0.5$ ), or the Beery Buktenica motor co-ordination $(p=0.59)$ except for Personal Social Quotients that tended to be lower in HIV+ children $(p=0.08)$. The Beery Buktenica Scales for visual motor integration $(p=0.23)$ and visual perception $(p=0.22)$ also tended to be lower in the HIV + group. The fact that these results were not significant at $5 \%$ could be due to a power problem (56\% for personal social and $37 \%$ 

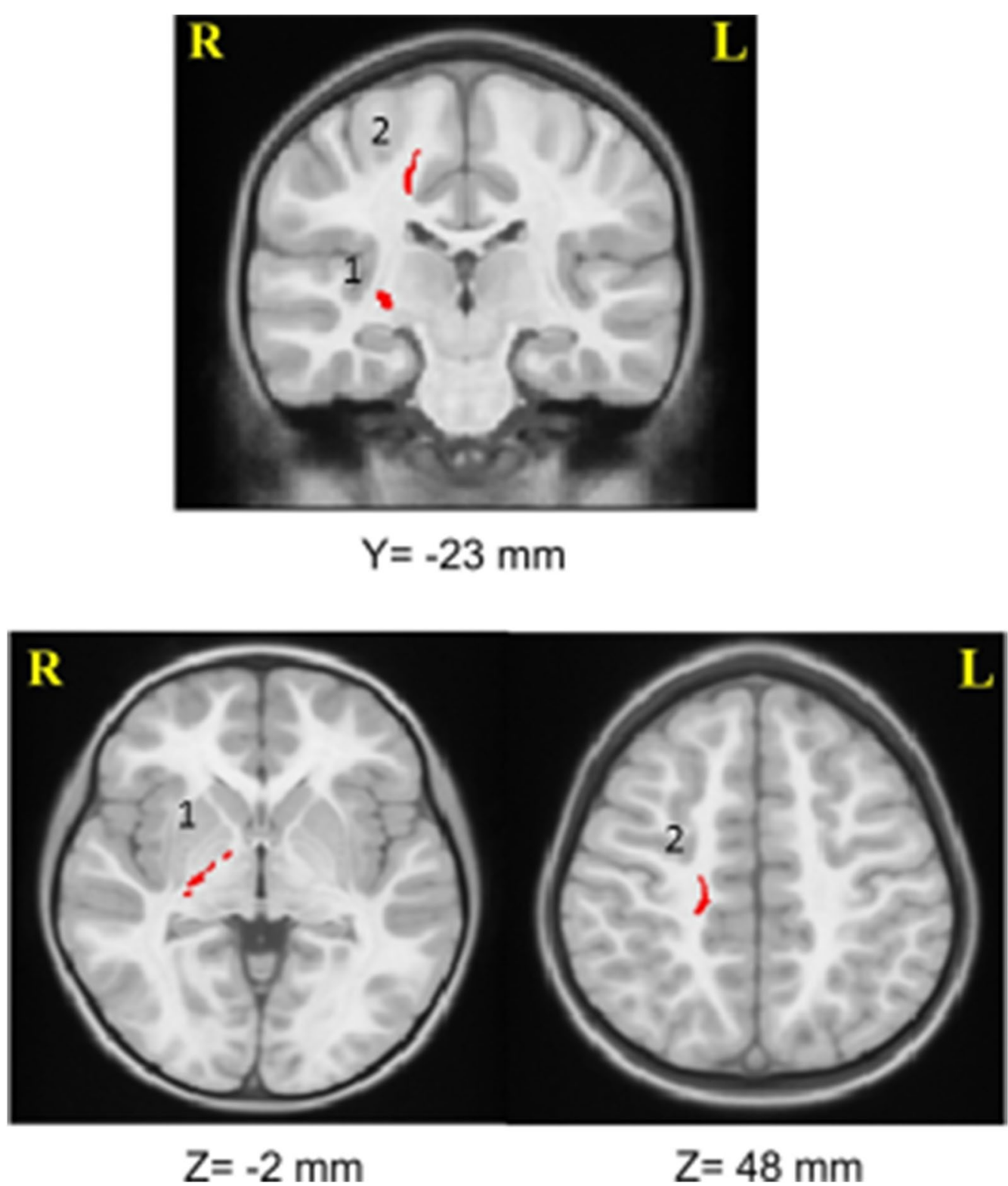

$\mathrm{Z}=48 \mathrm{~mm}$

Fig. 1 Two clusters in the right corticospinal tract, where FA was lower in HIV+ children than in controls. (1 = right internal capsule, $2=$ right parietal lobe)

for Beery Buktenica scales using independent samples $t$ test) but it did show the expected trends.

\section{Correlation of FA and MD with WM-directed neurodevelopmental tests}

Previously, we found lower FA in CST, and higher MD in ILF, SLF, CST, IFOF, forceps minor and UF, in HIV+ children than controls (Figs 1 and 2) [18].
Table 3 describes the clusters and neurodevelopmental tests selected for correlation. Overall, the Beery visual perception was negatively correlated with $\mathrm{RD}$ in the right temporal SLF $(r=-0.31, p=0.03)$ and left putamen region of the ILF $(r=-0.29, p=0.05)$. In left forceps minor, higher $\mathrm{AD}$ was related to increases in Practical Reasoning scores $(r=0.32, p=0.03$,), while $\mathrm{RD}$ in the same region showed a strong negative correlation with Personal-Social scores in the controls only $(r=-0.62$, 

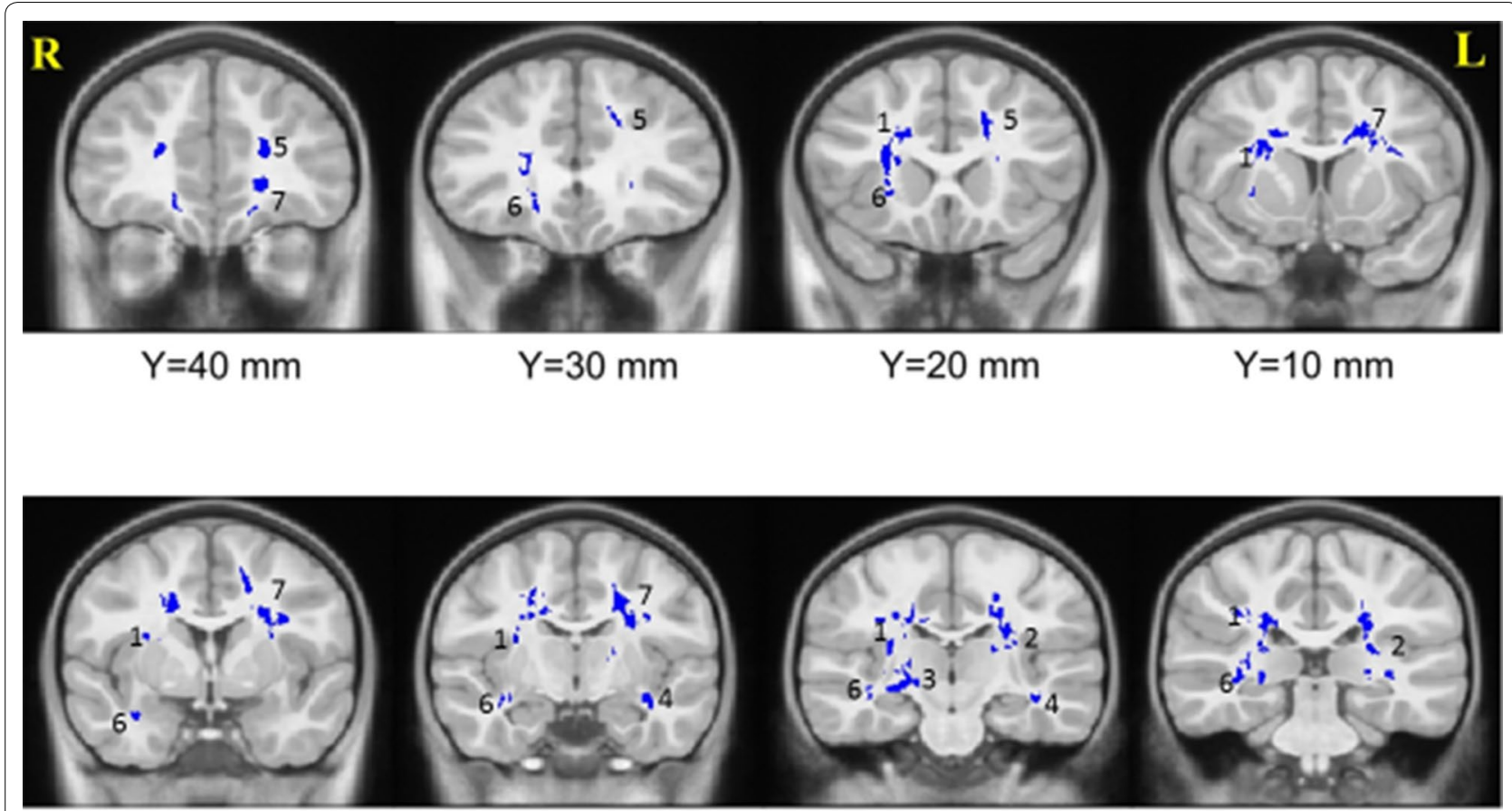

\section{$\mathrm{Y}=0 \mathrm{~mm}$}

$\mathrm{Y}=-10 \mathrm{~mm}$

$\mathrm{Y}=-20 \mathrm{~mm}$

$\mathrm{Y}=-30 \mathrm{~mm}$

Fig. 2 Seven clusters with higher MD in infected children compared to controls. ( $1=$ right SLF, $2=$ left ILF, $3=$ right CST, $4=$ left IFOF, $5=$ left forceps minor, $6=$ right uncinate fasciculus, $7=$ left forceps minor)

$p=0.05)$. In the HIV + group, negative correlations were found between Performance subscale scores and RD in the right UF $(r=-0.32, p=0.05)$, and between Beery Motor Coordination and AD in the brainstem in the CST $(r=-0.33, p=0.05)$. See Figs. 3, 4, 5, 6, 7, 8 .

\section{Discussion}

In this study we aimed specifically to examine the potential role of HIV-related WM alterations on neurodevelopmental outcomes, by examining correlations of WM measures with scores on functional domains where affected tracts play a critical role. In view of the increases in RD and AD observed in HIV+ children the associations point to impairment in visual perception, motor coordination and performance (which essentially test visuospatial skills), all of which have been described in $\mathrm{HIV}+$ children $[2,31]$.

In contrast to most previous studies that demonstrated clear differences between HIV+ and uninfected children on various functional domains [12, 32, 33], children in our study performed similarly at this age on all administered tests. Even in the larger group from the CHER neurodevelopmental sub-study, only visual perception deficits were detected in the HIV+ children at age 5 years [11]. Our findings support those of a recent metaanalysis which concluded that both general intellectual functioning and motor coordination are less impaired in HIV+ children than previously believed [2]. Various factors may explain the different study outcomes, including differences in methodologies, study populations and treatment regimens. The sample studied here comprised children of similar age and socio-economic background with a very well documented treatment history. All had commenced treatment by 18 months and achieved viral suppression by 49 months (median age at first viral suppression was 10 months). In view of the homogeneity and early treatment of these children, it is perhaps not surprising that their neurodevelopmental scores were minimally impaired compared to controls. Alternatively, it is possible that the battery of tests selected are not sensitive enough to detect the subtle impairments or that the sample size was too small to determine differences evident at this age.

It is known that WM integrity is correlated with cognitive performance in a fibre specific manner. [34]. For example, in stroke patients, the degree of CST injury, defined by DTI, correlates with motor impairment 
Table 3 WM tracts in which clusters showing FA reductions and MD increases in HIV + children compared to controls are located, the function of the implicated tracts and neurodevelopmental tests that assess said function

\begin{tabular}{|c|c|c|c|}
\hline Tract & Tract function [53] & $\begin{array}{l}\text { Griffiths mental development scales } \\
\text { Subscale used }\end{array}$ & $\begin{array}{l}\text { Beery-Buktenica } \\
\text { test of visual motor } \\
\text { integration }\end{array}$ \\
\hline Corticospinal Tract & $\begin{array}{l}\text { Descending projection fibres connecting } \\
\text { motor area to the spinal cord. Arise from } \\
\text { motor cortex of pre- and postcentral gyrus }\end{array}$ & Locomotor & Beery motor Co-ordination \\
\hline $\begin{array}{l}\text { Superior Longitudinal } \\
\text { Fasciculus }\end{array}$ & $\begin{array}{l}\text { Association fibres-unite different cortical } \\
\text { areas within the same hemisphere. Bidi- } \\
\text { rectional bundles connecting the frontal } \\
\text { lobe to the parietal, temporal and occipital } \\
\text { lobes } \\
\text { Function: integration of auditory and speech } \\
\text { nuclei, spatial awareness and symmetric } \\
\text { processing } \\
\text { Interruption decreases the ability to repeat } \\
\text { spoken language and can also cause } \\
\text { unilateral neglect }\end{array}$ & $\begin{array}{l}\text { Hearing and Language } \\
\text { Eye and Hand Coordination } \\
\text { Performance }\end{array}$ & $\begin{array}{l}\text { Beery-VMI } \\
\text { Beery-Visual Perception }\end{array}$ \\
\hline $\begin{array}{l}\text { Inferior Longitudinal } \\
\text { Fasciculus }\end{array}$ & $\begin{array}{l}\text { Connects the cortices of the anterior tem- } \\
\text { poral and posterior occipital lobe and joins } \\
\text { the inferior aspect of the SLF } \\
\text { Function: visual emotion and visual memory } \\
\text { Interruption may result in unilateral visual } \\
\text { neglect, visual amnesia and hallucinations } \\
\text { and also visual hypo emotionality }\end{array}$ & $\begin{array}{l}\text { Eye and Hand Coordination } \\
\text { Performance } \\
\text { Practical Reasoning }\end{array}$ & $\begin{array}{l}\text { Beery-VMI } \\
\text { Beery-visual perception }\end{array}$ \\
\hline Inferior Fronto Occipital Fasciculus & $\begin{array}{l}\text { Connects the ipsilateral frontal and occipital, } \\
\text { posterior parietal and temporal lobes. } \\
\text { Function: integration of auditory and visual } \\
\text { association cortices with the prefrontal } \\
\text { cortex }\end{array}$ & $\begin{array}{l}\text { Personal-Social } \\
\text { Language } \\
\text { Practical Reasoning }\end{array}$ & $\begin{array}{l}\text { Beery-VMI } \\
\text { Beery-Visual Perception }\end{array}$ \\
\hline Forceps Minor & $\begin{array}{l}\text { The forceps minor is the anterior part of the } \\
\text { corpus callosum, it connects the homolo- } \\
\text { gous regions of the anterior frontal lobes } \\
\text { between two hemispheres. Among the } \\
\text { regions included are the front polar cortex } \\
\text { which has been shown to be important } \\
\text { for cognitive behavioural control, decision } \\
\text { making, and attention control }\end{array}$ & $\begin{array}{l}\text { Personal-Social } \\
\text { Language } \\
\text { Performance } \\
\text { Practical Reasoning }\end{array}$ & \\
\hline Uncinate Fasciculus & $\begin{array}{l}\text { Connects the orbital and inferior frontal gyri } \\
\text { rectus to the anterior temporal lobe. It } \\
\text { has the longest period of development in } \\
\text { terms of FA and is the only WM tract that } \\
\text { continues to develop beyond } 30 \text { years } \\
\text { Part of the limbic system } \\
\text { Integrity of the tract has been related to } \\
\text { proficiency in auditory-verbal memory } \\
\text { and declarative memory }\end{array}$ & $\begin{array}{l}\text { Language } \\
\text { Performance } \\
\text { Practical reasoning }\end{array}$ & \\
\hline
\end{tabular}

$R$ right, $L$ left, CST corticospinal tract, SLF superior longitudinal fasciculus, ILF inferior longitudinal fasciculus, IFOF inferior fronto occipital fasciculus, UF uncinate fasciculus

[35-38]. The SLF plays an important role in higher brain functions particularly language, [39, 40], spatial awareness and symmetric processing [41]. The ILF is involved in visual memory $[42,43]$ and the UF in the formation and retrieval of memories [34, 44]. Studies in patients with multiple sclerosis also found a relationship between working memory performance and fibres of the SLF and IFOF [45]. The negative correlation found here between visual perception and RD in the SLF and ILF, provides additional evidence that these tracts have a role in interpreting visual information. Although in our small subsample, we did not detect group differences on Beery Visual Perception test, this domain did show HIV-related deficits in the larger sample assessed in the CHER neurodevelopmental sub-study [11]. Notably, the control group in our sub-sample comprised largely HIV-exposed 


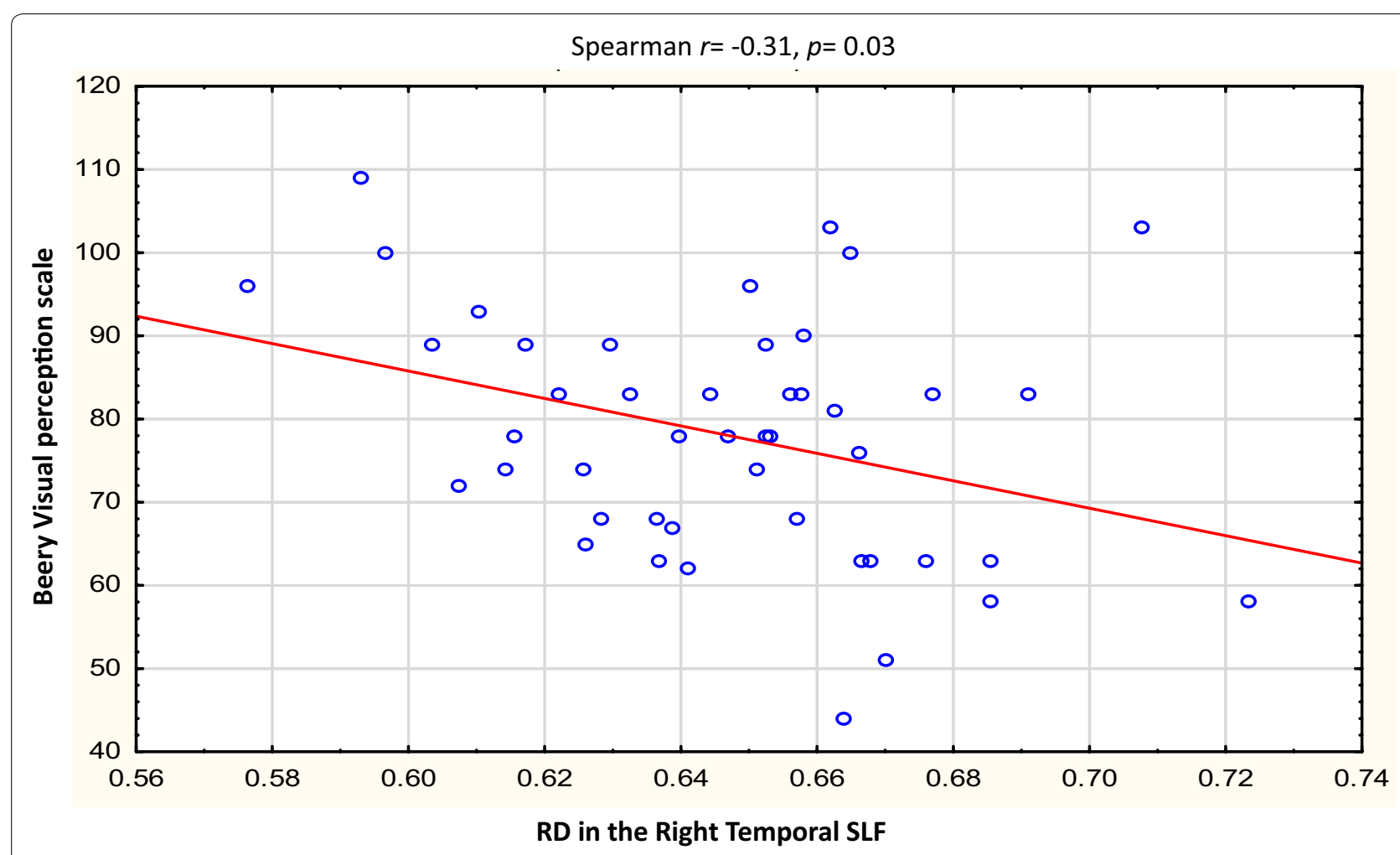

Fig. 3 Correlations of FA and MD with WM-directed neurodevelopmental tests. Overall, increasing RD in the right temporal SLF was associated with poorer performance on Beery visual perception

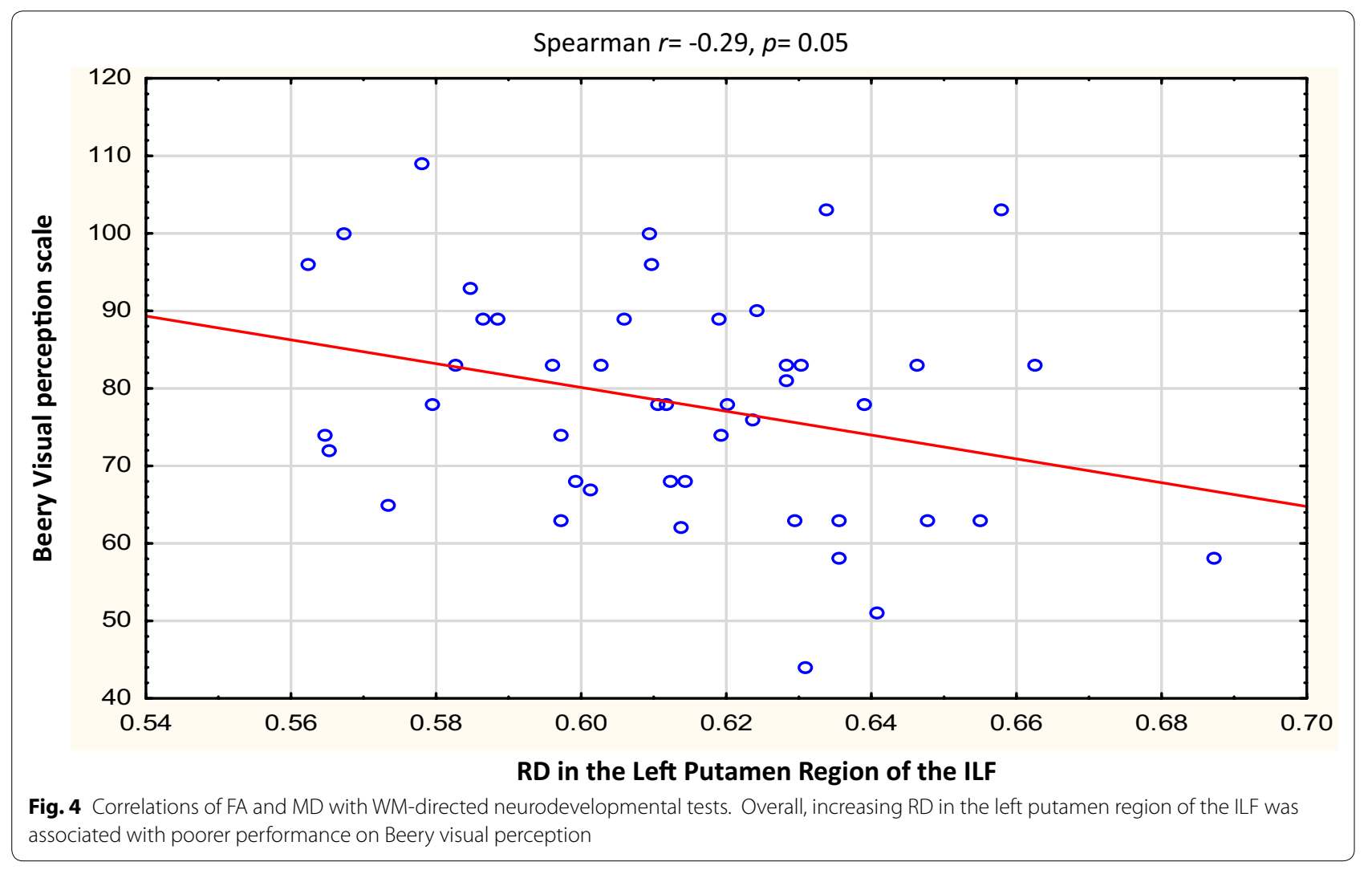




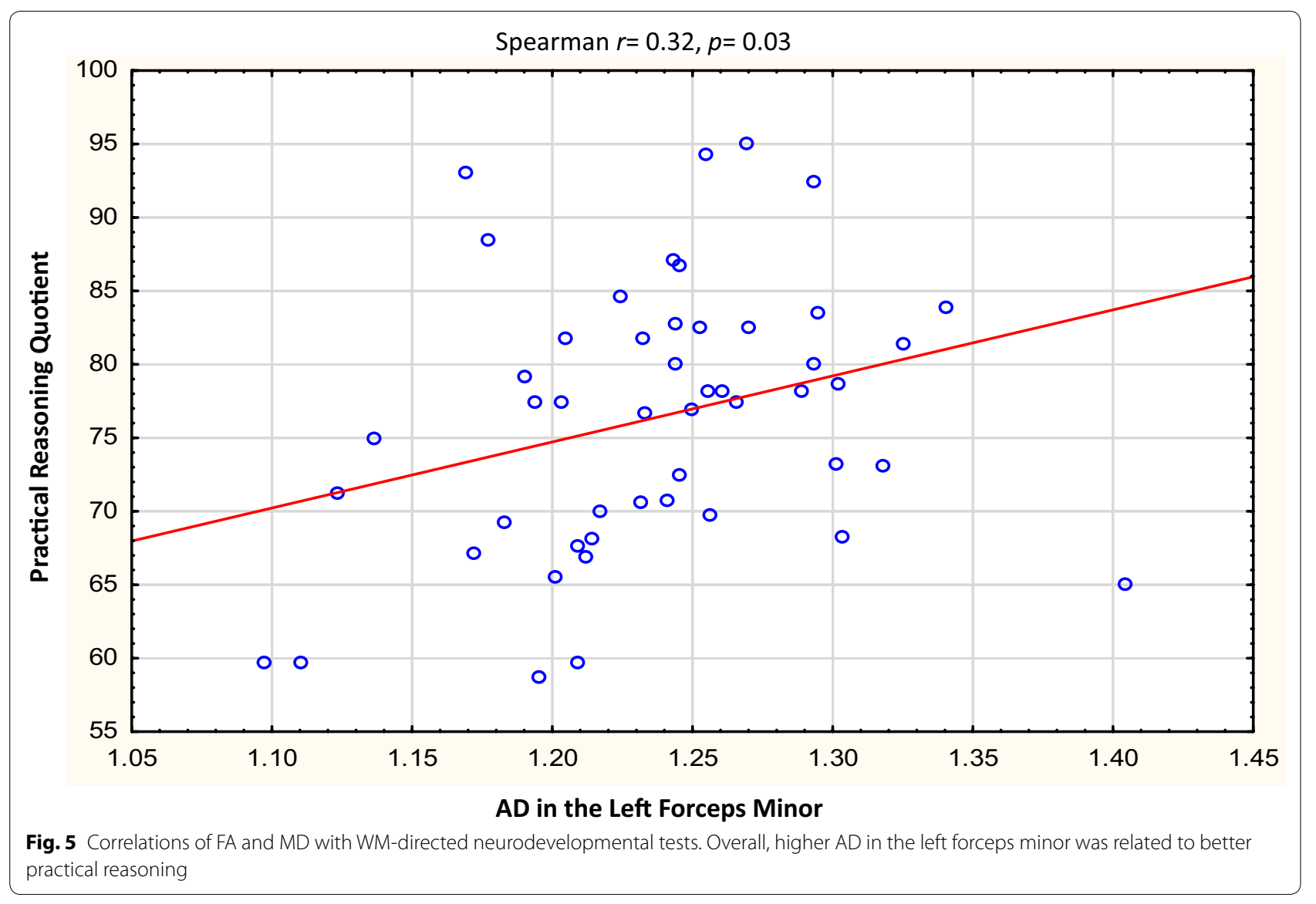

uninfected children (HEU), which may also be affected by perinatal HIV and ART exposure and explain our failure to detect developmental differences on this domain.

Visual perception, encompassing the appreciation of an object's qualities and its location in space, is dependent on the processing of visual information in the inferior temporal and posterior parietal cortices, respectively [46]. If perception is incorrect or altered in any way, problems with reading, spelling, handwriting, mathematics and comprehension can occur.

Ventral (occipitotemporal) and dorsal (occipitoparietal) visual pathways exist which are functionally specialized. Dorsal stream functions are related to spatial processing and control of visually guided actions and ventral stream functions to perceptual identification [46, 47] The most important WM trajectories of the ventral stream are the ILF and the IFOF [47] also described as intrahemispheric visual association WM tracts, as well as the UF [48]. It is striking that all three of these tracts demonstrated abnormalities in our HIV+ children.
The ventral visual stream is almost adult-like at 5-7 years of age, with DTI metrics demonstrating a rapid increase in FA and decrease in MD in the ILF between ages 5-7 years [47], placing the children in our study at a critical age in maturation of WM tracts for visual perception. HIV-associated WM damage described as being predominantly altered myelination [18], may well account for the abnormalities in visual perception identified by Laughton et al. and the trend demonstrated in the Beery Visual perception test in this group.

Increased AD in the left forceps minor was associated with improved practical reasoning for the group as a whole. Paradoxically, this could lead one to assume that HIV+ children may have better practical reasoning skills. Notably, we failed to detect a group difference for this domain in the current sample or the larger CHER substudy. The Practical Reasoning subscale assesses earliest arithmetic comprehension and the ability to solve very basic practical problems. The forceps minor connects the lateral and medial surfaces of the frontal lobes and 


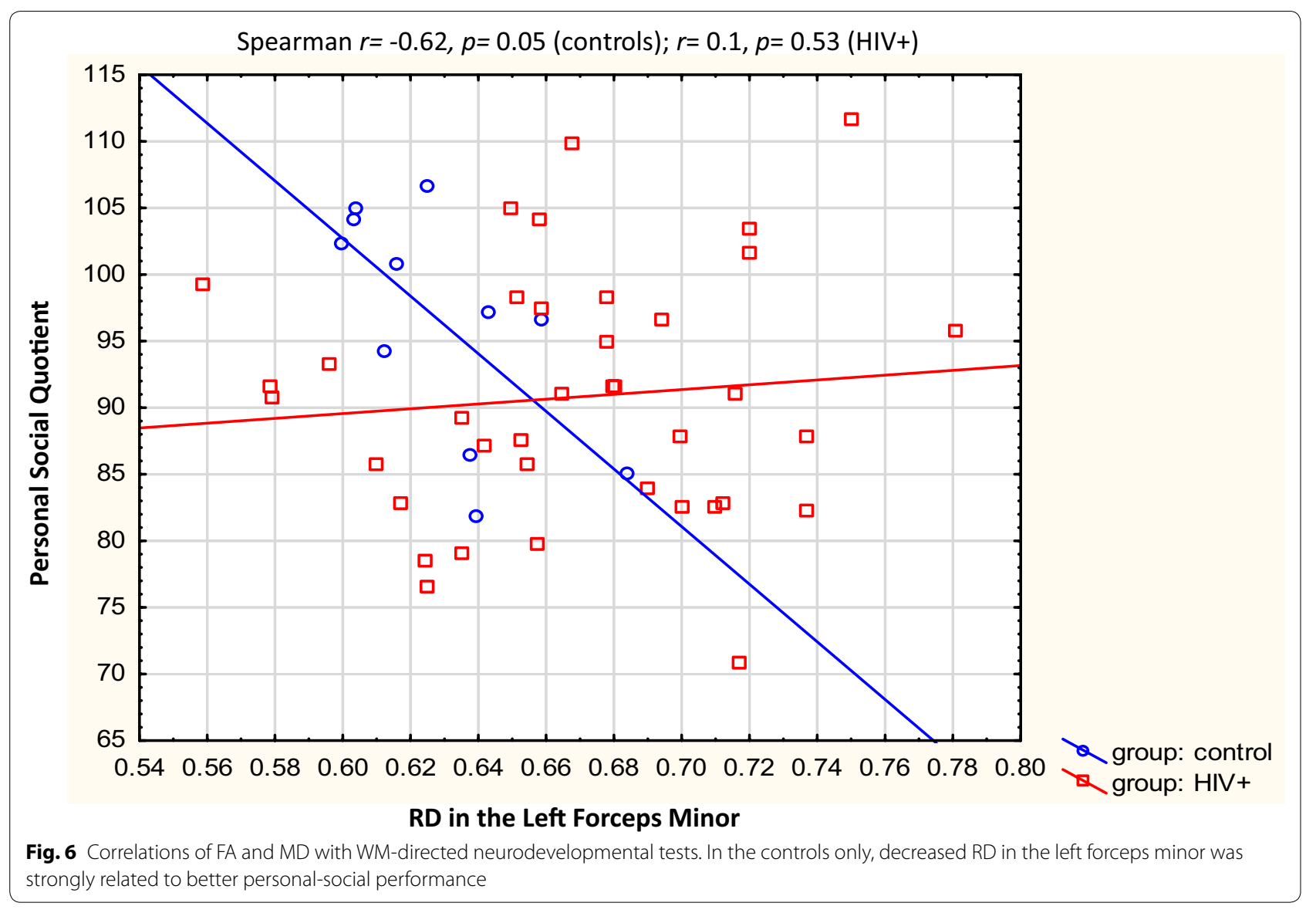

crosses the midline via the genu of the corpus callosum. It is an interhemispheric sensory and auditory connection pathway involved in emotional functions and behavioural control $[49,50]$. It may play an important role in mathematical skills as indicated in a study where children with increased mathematical ability demonstrated higher FA in WM tracts, particularly the forceps minor and major tracts connecting the frontal lobes with basal ganglia and parietal regions [51]. In our study however, we did not find higher FA but rather increased MD in the forceps minor.

When comparing neurodevelopmental performance between HIV+ and uninfected groups, only the Personal-Social Quotient showed a trend of being lower in HIV+ children $(p=0.08)$. However, this finding does not appear to be attributable to observed WM deficits, as WM measures from clusters in neither the IFOF nor the forceps minor showed association with PersonalSocial scores. The strong negative correlation between
RD in left forceps minor and Personal Social Quotient among controls suggest that increased myelination (characterised by $\mathrm{RD}$ reductions) in this tract may relate to improved personal and social development.

We acknowledge that the sample size (particularly of the control group) is small which may influence the power and increase the possibility of type II errors. The personal-social subscale is the most subjective test and relies on caregiver report for many self-care items. P-values for comparison of the neurodevelopmental scores on other subscales between the HIV+ and control children are all above 0.5 even as high as 0.81 for the General quotient.

Among HIV+ children, increased RD in the right frontal UF is associated with lower scores on the Performance subscale which assesses visuospatial skills, speed and precision. The UF, which connects the hippocampus and amygdala in the temporal lobe with the orbitofrontal cortex, is involved in working memory. This domain 


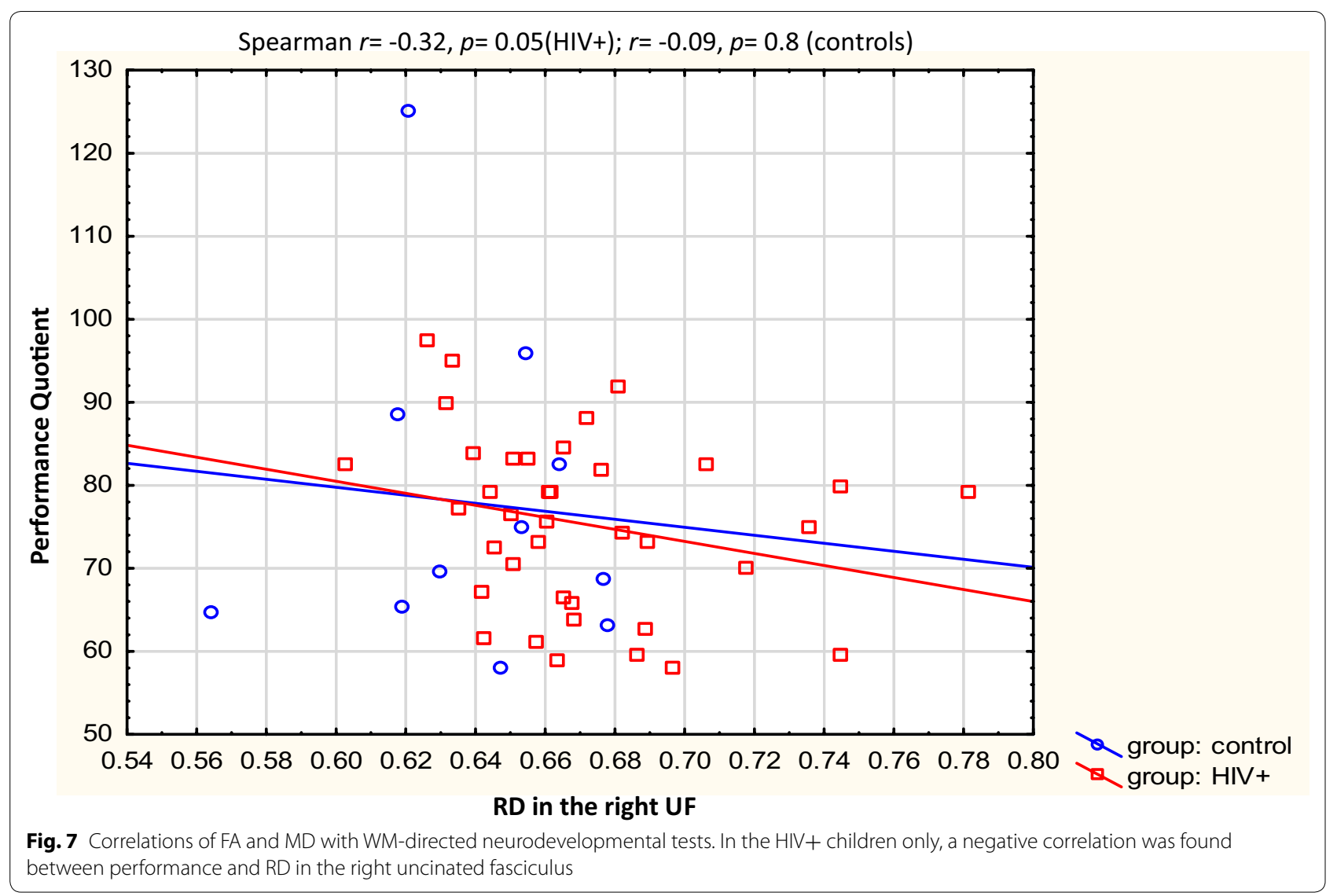

was identified as being affected by HIV in the meta-analysis by Phillips and colleagues [2]. It could be that this component of visuospatial processing leads to impaired performance only in the children with the highest RD's, who were from the HIV+ group. Unfortunately working memory was not assessed as a separate domain in our study.

Increased $\mathrm{AD}$ in the brainstem region of the CST is associated with poorer Beery motor coordination test scores in the HIV+ children. Three clusters with abnormal FA and MD in the CST compared to controls were found in the HIV+ group, however no performance differences were found in either the GMDS motor function or the Beery motor coordination. Locomotor deficits were present in this group at a younger age [11] therefore these findings may suggest that conventional neurodevelopmental assessments at this age are not sensitive enough to detect persistent deficits.

Notably, the WM deficits in the UF and brainstem region of the CST (regions that demonstrate association with performance measures in the HIV + group only) were not evident when the children in the current study were re-assessed at 7 years [52], indicating that these deficits may represent a developmental delay that resolves at later ages. In contrast, WM alterations in the ILF and forceps minor persist at age 7 years, suggesting that effects on visual perception may be more long-term or even permanent.

Limitations of this study are the small sample size of controls and the large number of HEU children (9 out of 11) in this group. The secondary effects of HIV and ART exposure in the HEU controls may have influenced neurodevelopmental scores and decreased our ability to detect neurodevelopmental differences between the infected and uninfected groups. On the other hand, this allowed for control of prenatal PMTCT drug administration and other factors such as living in a home affected by HIV. The study group is uniquely homogenous for age, timing of ART and socioeconomic background and 


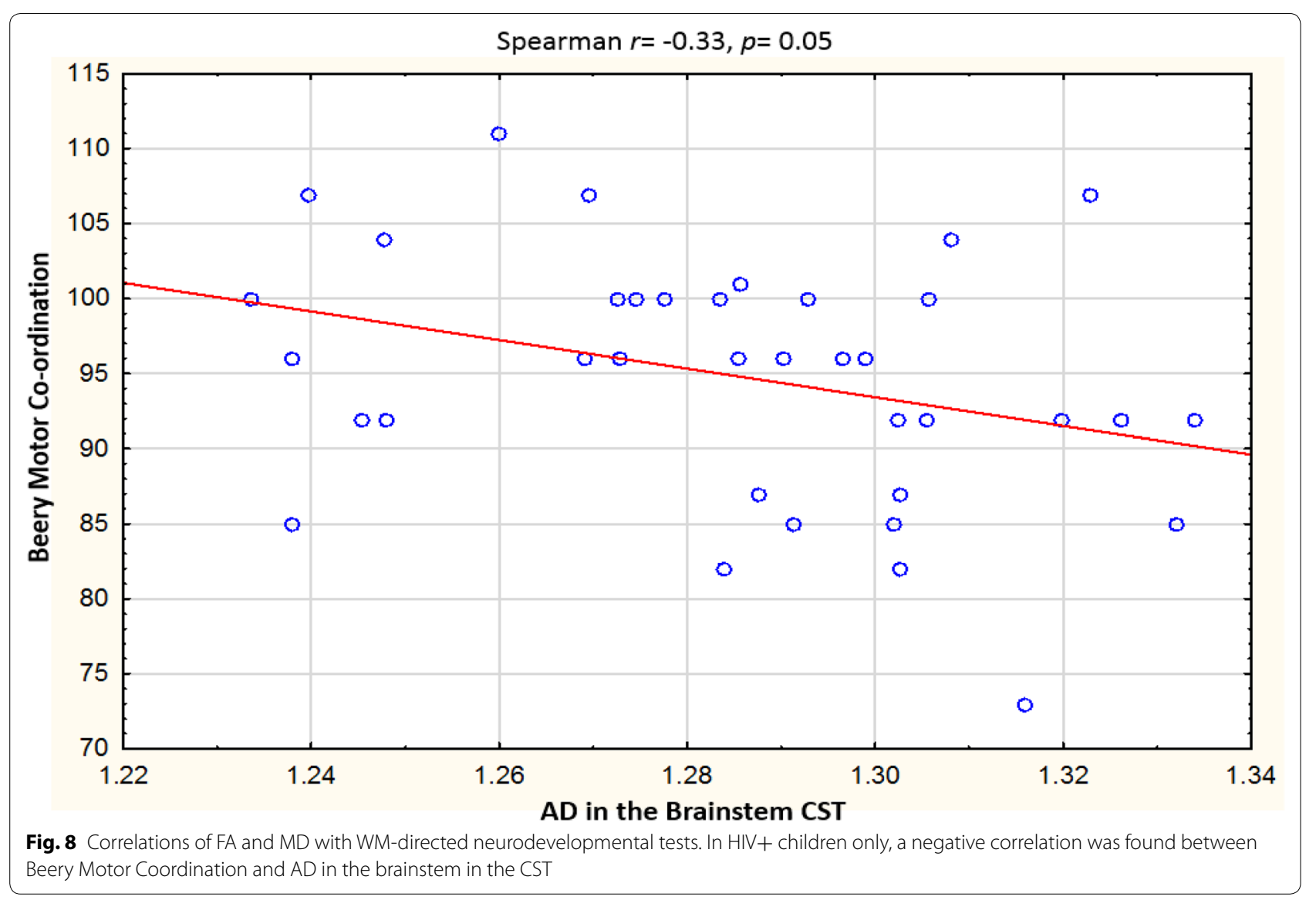

the cultural similarity also decreases bias between the groups.

\section{Conclusion}

Although the detrimental effect of HIV on WM is ameliorated by early ART, regional WM alterations on DTI MRI remain and show association at age 5 years with specific functional domains, including visual perception, performance, and motor coordination. In view of the visual perception deficit reported in these children at this age, the effect of HIV on the visual perception pathway should be further examined in a larger study group. Our findings suggest that brain imaging is more sensitive for subtle alterations from HIV and/or ART than standard neurodevelopmental tests.

\section{Supplementary information}

Supplementary information accompanies this paper at https://doi. org/10.1186/s12981-020-00278-z.

Additional file 1. The dataset supporting the conclusions of this article is included within the article as an additional file nr.1. (.xls 5 year old tabular data).

\section{Abbreviation}

ART: Combination antiretroviral therapy; CHER: Children with HIV early antiretroviral trial; Beery-VMI: Beery visual motor integration test; GMDS: Griffith's mental developmental scales; DTI: Diffusion tensor imaging; WM: White matter; FA: Fractional anisotropy; MD: Mean diffusivity; RD: Radial diffusion; AD: Axial diffusion; CST: Corticospinal tract; SLF: Superior longitudinal fasciculus; ILF: Inferior longitudinal fasciculus; IFOF: Inferior frontal occipital fasciculus; UF: Uncinate fasciculus; MRI: Magnetic resonance imaging; ART-Def: ART deferred; ART-40W: Early limited ART for 40 weeks; ART-96W: Early limited ART for 96 weeks; VL: Viral load; ANOVA: Analysis of variance; HEU: HIV exposed uninfected.

\section{Acknowledgements}

We thank GlaxoSmithKline/ViiV Healthcare and the Departments of Health of the Western Cape and Gauteng for supporting the CHER trial.

\section{Authors' contributions}

CA: principal investigator, interpreted the data and drafted the manuscript. SA: conception, analysis and revising the manuscript. MGS: analysis and interpretation of imaging data. MK: statistical analysis of data. MFC: revising manuscript for important intellectual content. BL and EMM: acquisition of data, analysis and interpretation of data, revising manuscript. All authors read and approved the final manuscript.

\section{Funding}

Research reported in this publication was supported by grants from the Harry Crossley Foundation, South African Medical Research Council (SAMRC), National Research Foundation grant CPR20110614000019421, NRF/DST South African Research Chairs Initiative, US National Institute of Allergy and Infectious Diseases (NIAID) through the CIPRA network, grant U19 AI53217; $\mathrm{NIH}$ grants R01HD071664 and R21MH096559. The content is solely the 
responsibility of the authors and does not necessarily represent the official views of the National Institutes of Health.

\section{Availability of data and materials}

All data generated or analysed during this study are included in this published article as Additional file 1.

\section{Ethics approval and consent to participate}

Ethics approval for the study was obtained from ethics boards of all institutions involved. Consent from caregivers and parents were obtained for all children involved in the study. Health research Ethics Committee (HREC) Stellenbosch University. Ethics reference nr's: N07/09/208; N05/05/092.

\section{Consent for publication}

No individual person's data contained in the manuscript. Not applicable.

\section{Competing interests}

The authors declare that they have no competing interests in this section.

\begin{abstract}
Author details
${ }^{1}$ Department of Radiodiagnosis, Faculty of Medicine and Health Sciences, University of Stellenbosch, Tygerberg, South Africa. ${ }^{2}$ Vice Chair of Research, Department of Paediatric Radiology, Children's Hospital of Philadelphia, Philadelphia, USA. ${ }^{3}$ MRC/UCT Medical Imaging Research Unit, Department of Human Biology, University of Cape Town, Cape Town, South Africa. ${ }^{4}$ Centre for Statistical Consultation, University of Stellenbosch, Stellenbosch, South Africa. ${ }^{5}$ Family Clinical Research Unit, Department of Paediatrics and Child Health, Faculty of Medicine and Health Sciences, University of Stellenbosch, Tygerberg, South Africa. ${ }^{6}$ Tygerberg Hospital, 4th Floor, Cape Town 7505 South Africa. ${ }^{7}$ CHOP, 3401 Civic Centre Blvd., Philadelphia 19104, USA. ${ }^{8}$ Stellenbosch University, Private Bag X1, Matieland 7602, South Africa. ${ }^{9}$ Present Address: Cape Town 7500, South Africa. ${ }^{10}$ UCT Faculty of Health Sciences, Barnard Fuller Building, Anzio road, Observatory, Cape Town 7935, South Africa. ${ }^{11}$ Present Address: Bellville 7530, South Africa.
\end{abstract}

Received: 25 February 2019 Accepted: 8 May 2020

Published online: 19 May 2020

\section{References}

1. Wachsler-Felder JL, Golden CJ. Neuropsychological consequences of HIV in children: a review of current literature. Clin Psychol Rev. 2002;22(3):441-62.

2. Phillips $\mathrm{N}$, et al. HIV-associated cognitive impairment in perinatally infected children: a meta-analysis. Pediatrics. 2016;138(5):e20160893-e20160893.

3. Crowell CS, et al. Early viral suppression improves neurocognitive outcomes in HIV-infected children. AIDS. 2015;29(3):295-304

4. Le Doare K, Bland R, Newell ML. Neurodevelopment in children born to HIV-infected mothers by infection and treatment status. Pediatrics. 2012;130(5):e1326-44.

5. Faye A, et al. Early versus deferred antiretroviral multidrug therapy in infants infected with HIV early versus deferred antiretroviral multi therapy in infants infected with HIV. Source Clin Infect Dis. 2004;39232(11):1692-8.

6. Collins IJ, Judd A, Gibb DM. Immediate antiretroviral therapy in young HIV-infected children: benefits and risks. Curr Opin HIV AIDS. 2014;9(1):87-94.

7. Bunupuradah T, et al. Outcomes after reinitiating antiretroviral therapy in children randomized to planned treatment interruptions. AIDS. 2013:27(4):579-89.

8. Ananworanich J, et al. Neurocognition and quality of life after reinitiating antiretroviral therapy in children randomized to planned treatment interruption. AIDS. 2016;30(7):1075-81.

9. Cotton MF, et al. Early time-limited antiretroviral therapy versus deferred therapy in South African infants infected with HIV: results from the children with HIV early antiretroviral (CHER) randomised trial. Lancet. 2013;382(9904):1555-63.

10. Kulp MT, Sortor JM. Clinical value of the Beery visual-motor integration supplemental tests of visual perception and motor coordination". Optom Vis Sci. 2003;80(4):312-5.
11. Laughton B, et al. Five year neurodevelopment outcomes of perinatally HIV-infected children on early limited or deferred continuous antiretroviral therapy. J Int AIDS Soc. 2018;21(5):e25106.

12. Blokhuis C, Kootstra NA, Caan MWA, Pajkrt D. Neurodevelopmental delay in pediatric HIV/AIDS: current perspectives. Neurobehav HIV Med. 2016;7(1):1-13.

13. Hoare J, et al. A diffusion tensor imaging and neurocognitive study of HIV-positive children who are HAART-naïve 'slow progressors. J Neurovirol. 2012;18(3):205-12.

14. Hoare J, et al. White-matter damage in clade c HIV-positive subjects: a diffusion tensor imaging study. J Neuropsychiatr Clin Neurosci. 2011:3:308-15.

15. Hoare J, et al. White matter micro-structural changes in ART-naive and ART-treated children and adolescents infected with HIV in South Africa. AIDS. 2015;29(14):1793-801.

16. Uban KA, et al. White matter microstructure among youth with perinatally acquired HIV is associated with disease severity. AIDS. 2015;29(9):1035-44.

17. Li J, et al. White matter development is potentially influenced in adolescents with vertically transmitted HIV infections: a tract-based spatial statistics study. Am J Neuroradiol. 2015;36(11):2163-9.

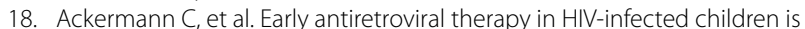
associated with diffuse white matter structural abnormality and corpus callosum sparing. AJNR. 2016;37(12):2363-9.

19. Violari $A$, et al. Early antiretroviral therapy and mortality among HIVinfected infants. N Engl J Med. 2008;21(20):2233-44.

20. Madhi SA, et al. Effect of HIV infection status and anti-retroviral treatment on quantitative and qualitative antibody responses to pneumococcal conjugate vaccine in infants. J Infect Dis. 2010;202(3):355-61.

21. Luiz D, Faragher B, Barnard A, et al. Griffiths mental development scalesextended Revised, two to eight years. Oxford: Hogrefe Test Agency Ltd; 2006.

22. Griffiths R. The Griffiths Mental Development Scales, from birth to 2 years. The 1996 Revision by Michael Huntley Association for research in infant and child development. Oxford: The Test Agency; 1996.

23. Beery KE, Beery NA. The Beery-Buktenica Developmental Test of VisualMotor Integration: Beery VMI administration, Scoring and Teaching Manual. 5, 6 ed. San Antonio TX: Pearson; 2004

24. Lowick S, Sawry S, Meyers T. Neurodevelopmental delay among HIV-infected preschool children receiving antiretroviral therapy and healthy preschool children in Soweto, South Africa. Psychol Health Med 2012:17(5):599-610

25. Luiz DM, Foxcroft CD, Stewart R. The construct validity of the Griffiths Scales of Mental Development. Child Care Health Dev. 1999;2791:73-83.

26. Reese TG, Heid O, Weiskoff RM, Wedeen VJ. Reduction of eddy-current induced distortions in diffusion MRI using a twice-refocused spin-echo. Magn Reson Med. 2003;49(1):177-82.

27. Tisdall MD, Hess AT, Reuter M, Meintjes EM, Fischl B, Van Der Kouwe AJW. Volumetric navigators for prospective motion correction and selective reacquisition in neuroanatomical MRI. Magn Reson Med. 2012;68(2):389-99.

28. Van der Kouwe AJW, Benner T, Salat DH, Fischl B. Brain morphometry with multiecho MPRAGE. Neuroimage. 2008;40(2):559-69.

29. Mori S, Wakana S, Nagae-Poetscher LM, Van Zijl PCM. Amsterdam. MRI atlas of human white matter. Am J Neuroradiol. 2006;27(6):1384-5.

30. Peters BD, et al. White matter development in adolescence: diffusion tensor imaging and meta-analytic results. Schizophr Bull. 2012:38(6):1308-17.

31. Ruel TD, et al. Neurocognitive and motor deficits in HIV-infected Ugandan children with high CD4 cell counts. HIV/AIDS. 2012;54(7):1001-9.

32. Cohen $\mathrm{S}$, et al. Cerebral injury in perinatally HIV-infected children compared to matched healthy controls. Neurology. 2016;86(1):19-27.

33. Whitehead N, Potterton J, Coovadia A. The neurodevelopment of HIVinfected infants on HAART compared to HIV-exposed but uninfected infants. AIDS Care. 2014;26(4):497-504.

34. Sasson E, Doniger GM, Pasternak $O$, Tarrasch $R$, Assaf Y. White matter correlates of cognitive domains in normal aging with diffusion tensor imaging. Front Neurosci. 2013;7:1-13.

35. Maraka S, et al. Degree of corticospinal tract damage correlates with motor function after stroke. Ann Clin Transl Neurol. 2014;1(11):891-9. 
36. Song J, et al. DTI measures track and predict motor function outcomes in stroke rehabilitation utilizing BCI technology. Front Hum Neurosci. 2015. https://doi.org/10.3389/fnhum.2015.00195.

37. Lindenberg SG, Renga V, Zhu LL, Betzler F, Alsop D. Structural integrity of corticospinal motor fibers predicts motor impairments in chronic stroke. Neurology. 2010;74(4):280-7.

38. Werring DJ, et al. Diffusion tensor imaging can detect and quantify corticospinal tract degeneration after stroke. J Neurol Neurosurg Psychiatry. 2000;69(2):269-72.

39. Catani $M$, et al. Axonal injury within language network in primary progressive aphasia. Ann Neurol. 2003;53(2):242-7.

40. Smits M, Visch-Brink EG, Van De Sandt-Koenderman ME, Van Der Lugt A. Advanced magnetic resonance neuroimaging of language function recovery after aphasic stroke: a technical review. Arch Phys Med Rehabil. 2012;93(Suppl 1):1-14.

41. Turken AU, Whitfield-Gabrieli S, Bammer R, Baldo JV, Dronkers NF, Gabrieli JDE. Cognitive processing speed and the structure of white matter pathways: convergent evidence from normal variation and lesion studies. Neuroimage. 2008;42(2):1032-44.

42. Shinoura N, et al. Impairment of inferior longitudinal fasciculus plays a role in visual memory disturbance. Neurocase. 2007;13(2):127-30.

43. Thomas C, Avidan G, Humphreys K, Jung KJ, Gao F, Behrmann M. Reduced structural connectivity in ventral visual cortex in congenital prosopagnosia. Nat Neurosci. 2009;12(1):29-31.

44. Levine $B$, et al. Episodic memory and the slef in a case of isolated retrograde amnesia. Brain. 2002;121:1951-73.

45. Walsh $\mathrm{M}$, et al. Object working memory performance depends on microstructure of the frontal-occipital fasciculus. Brain Connect. 2011;1(4):317-29.
46. Goodale MA, Milner AD. Separate visual pathways for perception and action. Trends Neurosci. 1992;15(1):20-5.

47. Loenneker T, Klaver P, Bucher K, Lichtensteiger J, Imfeld A, Martin E. Microstructural development: organizational differences of the fiber architecture between children and adults in dorsal and ventral visual streams. Hum Brain Mapp. 2011;32(6):935-46.

48. Thomas C, Humphreys K, Jung KJ, Minshew N, Behrmann M. The anatomy of the callosal and visual-association pathways in high-functioning autism: a DTI tractography study. Cortex. 2011;47(7):863-73.

49. Rametti $G$, et al. White matter microstructure in female to male transsexuals before cross-sex hormonal treatment. A diffusion tensor imaging study. J Psychiatr Res. 2011;45(2):199-204.

50. Kringelbach ML, Rolls ET. The functional neuroanatomy of the human orbitofrontal cortex: evidence from neuroimaging and neuropsychology. Prog Neurobiol. 2004;72(5):341-72.

51. Navas-Sanchez FJ, et al. White matter microstructure correlates of mathematical giftedness and intelligence quotient. Hum Brain Mapp. 2014;35(6):2619-31.

52. Jankiewicz M, et al. White matter abnormalities in children with HIV infection and exposure. Front Neuroanat. 2017:11:1-9.

53. Wycoco V, Shroff M, Sudhakar S, Lee W. White matter anatomy. What the radiologist needs to know. Neuroimaging clinics of North America. 2013;23(2):197-216.

\section{Publisher's Note}

Springer Nature remains neutral with regard to jurisdictional claims in published maps and institutional affiliations.
Ready to submit your research? Choose BMC and benefit from:

- fast, convenient online submission

- thorough peer review by experienced researchers in your field

- rapid publication on acceptance

- support for research data, including large and complex data types

- gold Open Access which fosters wider collaboration and increased citations

- maximum visibility for your research: over $100 \mathrm{M}$ website views per year

At BMC, research is always in progress.

Learn more biomedcentral.com/submissions 